Pesquisa e Reflexão em Educação Básica

\title{
Quem são os jovens do Ensino Médio?
}

\begin{abstract}
Resumo:
Este artigo situa-se no debate atual envolvendo a relação da juventude com a instituição escolar. $O$ objetivo é compreender quem são os jovens que frequentam o ensino médio público na cidade de Goiânia, Goiás. Para tal, além da discussão sociológica sobre a juventude, foi realizada uma pesquisa de campo com a aplicação de questionários para 297 estudantes. A partir das respostas, foram criadas três categorias: 1) os jovens que acreditam que a juventude é uma fase para aproveitar a vida com liberdade; 2) os jovens que veem a juventude como uma fase de amadurecimento/responsabilidade; $e, 3)$ aqueles que não responderam a pergunta. No intuito de classificar os grupos, o primeiro deles foi chamado de "juvenilistas"; o segundo de "passageiros" e o terceiro de "invisíveis". Conclui-se pela necessidade de compreender os jovens estudantes, já que é por meio desta compreensão que se chega ao entendimento de que a juventude hodierna tem vivenciado (ou sofrido) processos heterogêneos de socialização e isso faz com que os jovens passem a serem mais percebidos socialmente como sujeitos capazes de tomar decisões e se posicionarem, inclusive dentro do ambiente escolar.
\end{abstract}

\section{Palavras-chave:}

Ensino Médio. Juventude. Escola.

\section{Who is the high school youth?}

\begin{abstract}
This article is part of the current debate involving the relationship of youth with the school institution. The objective is to understand who are the young people who attend public high school in the city of Goiânia, Goiás. For this, in addition to the sociological discussion about youth, a field survey was carried out with the application of questionnaires for 297 students. From the responses, three categories were created: 1) young people who believe that youth is a phase to enjoy life with freedom; 2) young people who see youth as a stage of maturity/responsibility; and, 3) those who did not answer the question. In order to classify the groups, the first one was called "juvenilistas"; the second for "passengers" and the third for "invisibles". It concludes by the need to understand young students, since it is through this understanding that the understanding that today's youth has experienced (or suffered) heterogeneous socialization processes and this makes young people become more perceived socially as subjects capable of making decisions and positioning themselves, including within the school environment.
\end{abstract}

Keywords: High School. Youth. School.

1 Doutor em Sociologia. Professor da Universidade Estadual de Goiás (UEG). E-mail: gabriel.bungenstab@ueg.br. ORCID iD: https://orcid.org/0000-0002-3100-1538. 


\section{Quiénes son los jóvenes de la escuela secundaria?}

Resumen: Este artículo es parte del debate actual sobre la relación de la juventud con la institución escolar. El objetivo es comprender quiénes son los jóvenes que van a la escuela secundaria pública en la ciudad de Goiânia, Goiás. Para ello, además de la discusión sociológica sobre la juventud, se realizó una pesquisa de campo con la aplicación de cuestionarios a 297 estudiantes. A partir de las respuestas se crearon tres categorías: 1) jóvenes que creen que la juventud es una etapa para disfrutar de la vida en libertad; 2) jóvenes que ven a la juventud como una etapa de madurez / responsabilidad; y, 3) aquellos que no respondieron la pregunta. Para clasificar los grupos, el primero se denominó "juvenilistas"; el segundo "pasajeros" y el tercero "invisibles". Se concluye por la necesidad de comprender a los jóvenes estudiantes, ya que es a través de esta comprensión que la comprensión de que la juventud de hoy ha vivido (o sufrido) procesos de socialización heterogéneos y esto hace que los jóvenes sean más percibidos socialmente como sujetos capaces de tomar decisiones y posicionarse, incluso dentro del entorno escolar.

Palabras clave: Escuela secundaria. Juventud. Escuela.

\section{Introdução}

A discussão sobre o ensino médio e a juventude gera inúmeros debates envolvendo tanto o mundo acadêmico como os atores políticos. Este artigo surge a partir das indagações apresentadas por Dayrell (2007) a respeito da escolarização da juventude na sociedade contemporânea. Dayrell se pergunta se a escola "faz" juventudes. Na tentativa de responder esta indagação, ele acredita que é necessário mudar o eixo das perguntas que envolvem a relação escola/juventudes. Assim, propõe que passemos das instituições sociais para os sujeitos jovens, ou seja, a escola tendo que ser repensada para responder os desafios que são colocados pela juventude atual. Nesse sentido, o objetivo deste artigo é tentar compreender quem são os jovens que frequentam o ensino médio público na cidade de Goiânia, Goiás ${ }^{1}$.

Para Abramo (1997), é sintomática a atenção dirigida aos jovens tanto por parte da opinião pública (veículos de comunicação de massa) quanto por parte das esferas políticas e instituições. Se por um lado a juventude recebe inúmeras propostas de produtos culturais, comportamentais e de consumo (lazer, moda, estilo de vida); por outro lado, ela é assunto na mídia, quase sempre, relacionada aos problemas sociais. A noção que os jovens têm de si está totalmente ligada as suas experiências e suas vidas cotidianas. Como bem ressalta Pais (2005, p. 66): "Para muitos jovens, as rotas do quotidiano são, muitas vezes, rotas de ruptura, rotas de desvios múltiplos. E são nestas rotas que emergem os valores juvenis mais contestatórios".

Segundo Dayrell (2013) e Reis (2012) a entrada de jovens que até então estavam longe da escola, fez esta instituição se abalar no que tange aos seus ritos, regras e conteúdos. Nesse sentido, Martins e Carrano (2011, p. 54) salientam para a necessidade de a escola deixar de enxergar os jovens de forma homogeneizada que precisa se adequar aos padrões de estudante proposto por essa instituição. As instituições como a escola, "[...] não se dão conta que as expectativas dos jovens com relação à vida e ao futuro não são mais as mesmas que aqueles que os seus principais representantes - os pais e professores - acreditam ser importantes para a participação em sociedade".

Ponto de partida interessante é entender que esses sujeitos não se constituem apenas como jovens, eles também podem ser filhos/pais, trabalhadores/desempregados, homens/mulheres e estudantes. Será que eles carregam consigo uma ideia de juventude como fase da vida? Ou será

1 Trata-se do recorte da tese de doutorado defendida pelo autor no ano de 2016 no Programa de Pós-Graduação em Sociologia da UFG. O artigo submetido é um texto revisado e atualizado do capítulo 3 da tese (BUNGENSTAB, 2016). 
que eles vão criando e recriando suas trajetórias de vida dentro de um contexto marcado pelas contradições? Para tentar responder a essas indagações, o presente artigo se debruça na análise de uma pergunta central realizada aos jovens estudantes pesquisados: 1) para você o que é ser jovem? Assim sendo, o itinerário reflexivo deste trabalho é composto por: 1) metodologia; 2) discussão teórica sobre juventude; 3) análise dos dados e; 4) conclusão.

\section{Metodologia}

De acordo com a subsecretaria do Estado de Educação, na capital Goiânia existem 78 escolas públicas de ensino médio. A ideia foi trabalhar metodologicamente lançando mão de aspectos quantitativos e qualitativos por meio de aplicação de questionários para 297 jovens estudantes de quatro escolas públicas de ensino médio de Goiânia. Apesar de o questionário ser historicamente associado nas pesquisas quantitativas, ele é uma importante ferramenta em prol de uma busca maior na riqueza dos dados se aproximando, assim, das características das pesquisas qualitativas (MACEDO, 2000).

Visto isso, foi realizada também uma análise de conteúdo com o intuito de entender os sentidos atribuídos às comunicações e as mensagens (escritas ou não) que surgiram durante o processo de investigação. De acordo com Bardin (1988), três são as etapas básicas no processo do uso de análise de conteúdo, a saber: pré-análise, exploração do material e interpretação dos dados (ALMEIDA; BUNGENSTAB, 2016, p. 157). As perguntas, no questionário, procuraram saber questões referentes às suas experiências cotidianas dentro da escola e se mudariam algo na mesma. Além da relevância da aplicação do questionário, enxergou-se também a importância na escolha das escolas a serem pesquisadas.

Para escolher as quatro escolas, optamos em abarcar aquelas que poderiam nos dar uma maior diversidade de experiências juvenis, ou seja, a escolha se deu baseada em fatores específicos e heterogêneos. O primeiro deles refere-se à localidade, pois acreditamos que, de acordo com o local em que estão situadas, as experiências juvenis dentro delas vão se modificando e se particularizando. Nesse sentido, das quatro escolas estaduais de ensino médio público, decidimos escolher duas escolas situadas em regiões próximas ao centro da cidade e duas escolas situadas em regiões mais afastadas do centro de Goiânia.

As escolas periféricas referem-se aquelas que se situam em regiões socioeconomicamente carentes (mesmo estando, muitas vezes, localizadas geograficamente próximas ao centro da cidade). Já as escolas centrais são aquelas que estão localizadas em regiões mais desenvolvidas (mesmo algumas estando geograficamente distante do centro da cidade) (ALMEIDA; BUNGENSTAB, 2016, p. 157). O segundo critério para a escolha das escolas foi em relação à quantidade de alunos(as). Selecionamos aquelas que tivessem no mínimo mil estudantes matriculados, já que a maior quantidade de alunos possibilitaria, também, o maior número de questionários respondidos.

O terceiro (e último) critério diz respeito à quais estudantes das escolas selecionadas iriam responder as perguntas do questionário. Como sabido, o ensino médio é composto por três etapas: primeira, segunda e terceira série. Pautado pela noção de experiência (DUBET, 1994), decidiu-se escolher as turmas de segundo ano do ensino médio. Acreditamos que os alunos do primeiro ano, por estarem vindo do ensino fundamental, ainda não construíram suas experiências a respeito do ensino médio, como também não desenvolveram lógicas de ações para lidar com esse cotidiano. Já os(as) estudantes do terceiro ano, apesar de já terem vivenciado suas experiências, estão na última etapa do ensino médio e poderiam estar menos dispostos a participar da pesquisa, uma vez que estariam próximos de encerrar seus ciclos nesta etapa de ensino. A escolha pelos jovens que cursam o segundo ano do ensino médio se deu, então, por acreditar que eles já possuem suas noções e experiências próprias dentro do espaço da escola, sobretudo no que tange as suas ações cotidianas, inclusive, em relação aos saberes e as atividades que lá são produzidas. 
No percurso metodológico foi aplicado um questionário ${ }^{2}$ (com perguntas fechadas e abertas) com duas turmas de segundo ano de cada escola estadual de ensino médio. As escolas centrais escolhidas foram (nomes fictícios): C1 (74 questionários) e o C2 (76 questionários). As escolas periféricas foram: P1 (75 questionários) e P2 (76 questionários). Somando as quatro escolas pesquisadas, foram aplicados 297 questionários aos jovens (como mostra a Tabela 1).

Tabela 1 - As escolas em números de estudantes

\begin{tabular}{cccc}
\hline Escola Estadual: & $\begin{array}{c}\text { Número de jovens } \\
\text { que responderam } \\
\text { o questionário: }\end{array}$ & $\begin{array}{c}\text { Número de jovens } \\
\text { cursando o segundo } \\
\text { ano do ensino médio: }\end{array}$ & $\begin{array}{c}\text { Total de alunos(as) } \\
\text { matriculados(as): }\end{array}$ \\
\hline C2 & 76 & 655 & 1733 \\
\hline C1 & 74 & 334 & 1334 \\
\hline P1 & 75 & 350 & 1065 \\
\hline P2 & 76 & 346 & 1045 \\
\hline
\end{tabular}

Fonte: Elaborado pelo autor.

O questionário foi o principal instrumento utilizado para coleta de dados. Ele pode ser definido como uma técnica de investigação que agrega várias questões que tem a intenção de saber informações sobre crenças, sentimentos, opiniões, valores e expectativa dos jovens.

\section{Sociologia da juventude: uma introdução}

No imaginário social existem discursos sobre "o que é ser jovem" que, nem sempre, estão afinados com aqueles discursos oriundos dos ambientes acadêmicos. A percepção hegemônica de juventude advinda do imaginário social parece ainda ser aquela que considera o jovem, exclusivamente, como um sujeito em transição ${ }^{3}$. Como transição, a juventude se configura como uma fase da vida que ruma para a idade adulta. Tal concepção, cristalizada nas idades da vida, denota a importância das instituições sociais no cuidado diante dos jovens. O objetivo de tal empreendimento é guiar e orientar a transição dos jovens, fazendo com que esta passagem seja segura e sem problemas. Segundo Bungenstab (2020, p. 4):

Em contrapartida a este discurso, há aquele que considera a juventude como uma categoria social, histórica e cultural. Assim, a juventude é mais do que simplesmente uma fase da vida e passa a se constituir nos seus diversos projetos, classes e marcadores sociais. A partir desta ideia não faz sentido considerar a juventude como uma categoria homogênea, mas sim pensá-la a partir de diferentes modos de 'ser jovem', sobretudo, a partir das diversas identidades e heterogeneidades.

Pais (2005), por exemplo, busca compreender os jovens nas suas ações e manifestações cotidianas, estudando as tramas que eles tecem com o espaço da cidade e também refletindo sobre os diferentes comportamentos de grupos juvenis, ora pautados pela intensa influência do tradicionalismo e ora influenciados pelas relações efêmeras contemporâneas que fazem emergirem situações neotribais.

2 A coleta de dados foi realizada entre os meses de março até junho de 2015.

3 Como representantes desta noção de juventude, destacamos Parsons (1942) e Eisenstadt (1956). 
É nessa esteira que Pais, Cairns e Pappámikail (2005) estudaram os diferentes grupos juvenis europeus no que tange a suas relações com a família, escola e o trabalho. Eles perceberam que a realidade juvenil europeia, no tocante as suas transições para a vida adulta, só podem ser percebidas se considerarmos as mais diferentes filiações identitárias que fazem parte da experiência e do cotidiano do mundo vivido por esses jovens. Dentre as mais diversas filiações identitárias, ter um emprego, concluir o ensino secundário e a relação familiar são aspectos que diferenciam as trajetórias juvenis.

Mesmo tecendo críticas as correntes geracionais e classistas, Pais (2009) dialoga com tais perspectivas, pois, entende que essas estão enraizadas nos discursos cotidianos dos indivíduos, principalmente daqueles que falam sobre o que é e o que deveria ser a juventude. Segundo Pais (2009, p. 374): "Se existem fases da vida é porque se encontram sujeitas a regularidades embora cada indivíduo possa viver singularmente o seu próprio curso de vida". No entanto, ele reconhece que temos assistido uma modificação no que tange as passagens da fase da juventude para a idade adulta. Essas modificações estão, principalmente, relacionadas ao emprego/desemprego, casamento/ divórcio e abandono/retorno à escola. Assim, há um reconhecimento de que são mais efêmeros e descontínuos os aspectos que delimitam as fronteiras entre as diferentes fases da vida.

Para o sociólogo brasileiro, então, a juventude é parte de um processo amplo da constituição dos sujeitos, mas que é acompanhada por especificidades que marcam a vida de cada indivíduo ou grupo. Dayrell (2003, p. 42), por sua vez, vai dizer que "é nesse sentido que enfatizamos a noção de juventudes, no plural, para enfatizar a diversidade dos 'modos de ser jovem' existentes. Assim compreendida, torna-se necessário articular a noção de juventude a de sujeito social”. Para falar sobre a ideia de sujeito social, o sociólogo brasileiro vai se basear nos escritos do também sociólogo Bernard Charlot (2013) que considera o sujeito como um ser humano aberto a um mundo que possui uma historicidade. Sujeito que é possuidor de desejos e se relaciona com outros seres humanos. É também um ser singular que tem sua história e sua forma particular de enxergar o mundo e dar sentido a ele, bem como, também, é um ser social que ocupa um determinado lugar na sociedade.

Dayrell (2003) pensa o jovem como sujeito social considerando, também, os processos desumanizadores que esses sujeitos experimentam em suas vidas. Para ele, esses processos, apesar de dificultarem a vida cotidiana juvenil, não privam os jovens de desenvolverem todas suas potencialidades. É a partir disso que os jovens vão construindo as suas particularidades e seus jeitos próprios de viver. Assim, para Dayrell (2003, p. 44):

Tomar os jovens como sujeitos não se reduz a uma opção teórica. Diz respeito a uma opção metodológica e ética [...]. A experiência da pesquisa mostrou-me que ver e lidar com o jovem como sujeito, capaz de refletir, de ter suas próprias posições e ações, é uma aprendizagem que exige um esforço de auto-reflexão, distanciamento e autocrítica.

Nota-se que Dayrell em todas suas obras (e pesquisas) tenta enxergar os sujeitos jovens situados em espaços e tempos com os quais eles podem vivenciar toda a sua condição juvenil. Espaços que podem ser grupos que carregam os estilos rap, funk e até mesmo práticas corporais. Desse modo, já nos anos de 2002 e de 2003 Dayrell (2003) atentava para transformações socioculturais que caminhavam numa "desinstitucionalização" das relações juvenis em prol de uma crescente vivência das relações de lazer, pautadas pela sociabilidade e pela partilha de estilos.

Ao trabalhar com a noção de condição juvenil, o sociólogo brasileiro vai dizer que nela existe uma dupla dimensão. A primeira relacionada a como a sociedade atribui e constitui a noção a esse momento da vida no que tange ao seu significado histórico-geracional e a segunda referente ao modo como cada condição juvenil é vivida a partir dos diferentes recortes realizados com as desigualdades sociais. A partir disso, Dayrell (2007) propõe um novo modelo de investigação no qual o intuito é menos de pensar o jovem (querendo moldá-lo, cercá-lo e dizer aquilo que essa categoria 
deve ou não fazer) e mais de modificar e repensar as estruturas que norteiam a juventude. A grande importância trazida nos estudos de Juarez Dayrell parece estar na sua sensibilidade em enxergar as participações juvenis que ocorrem de forma diversa em espaços públicos que se desenvolvem as margens das formas tradicionais de participação juvenis institucionalizadas.

Pais (1990), assim como Dayrell, não pensa na juventude como uma categoria alienatória passível de manipulação. Ele não considera os jovens como uma categoria homogênea. Considera, portanto, a juventude como elemento heterogêneo que possui diferenças que ultrapassam as relações de classe. A corrente geracional e a corrente classista também são criticadas por Pais já que, segundo ele, essas correntes buscavam sempre normatizar e classificar os comportamentos juvenis. Assim, para o pensador português, entender os jovens é, sobretudo, entender seus modos de vida. Podemos afirmar que tanto Pais como Dayrell consideram a autonomia e as possibilidades de escolha de cada jovem. Eles parecem enxergar uma possível relativização da juventude atual e, ao se aproximarem da ideia de modernidade reflexiva de Giddens (1991), acabam considerando que as relações entre os jovens e as instituições podem ocorrer de forma dialética.

\section{Análises e resultados: os jovens de Ensino Médio}

Os dados dos questionários respondidos pelos jovens nos mostram que, além deles estarem cursando o segundo ano, também estão inseridos na faixa etária que vai de 14 a 19 anos. Dos 297 jovens pesquisados, 160 correspondem ao sexo masculino e 137 ao sexo feminino. Os jovens pesquisados tiveram a oportunidade de se definirem como estudantes: $67 \%$ das jovens meninas se definiram como boas e/ou muito boas estudantes, $33 \%$ como regulares e nenhuma como ruim. Já em relação aos meninos, $78 \%$ se definiram como bom e/ou muito bom estudante, $22 \%$ como regulares e nenhum se classificou como estudante ruim. Interessante notar que a maioria das respostas de ambos os gêneros definiram o "bom aluno" como alguém que quer aprender, estudar, tirar boas notas e ter bom comportamento. Em qualquer uma dessas definições nenhum jovem de ambos os sexos afirmou ser um aluno ruim.

De todos os jovens pesquisados, apenas 15 são maiores de idade, sendo que, desses, nove são mulheres. 204 jovens possuem idade entre 15 e 16 anos. Notamos ainda que a grande maioria dos(as) jovens pesquisados estavam solteiros(as) e, em sua maioria, não trabalhavam. O trabalho está mais presente na vida das jovens meninas do que dos meninos (mesmo elas estando em número menor). Os jovens participantes da pesquisa relatam ter boa relação com seus pares e em sua maioria fazem parte de algum grupo de amigos. Podemos afirmar que estamos diante de jovens que majoritariamente são menores de idade, solteiros, que moram em diferentes regiões da cidade, convivem com as perspectivas de trabalho e possuem seus entendimentos sobre quais papéis devem desempenhar na escola para serem bons alunos e alunas. Traçar um perfil dos(as) jovens estudantes é importante pois nos permite revelar alguns aspectos interessantes: o fato de estes(as) jovens viverem em bairros com pouca infraestrutura e estarem inseridos(as) em escolas públicas de ensino médio nos mostra que suas condições juvenis podem ser marcadas por desafios constantes.

Concordamos com Dayrell e Carrano (2014) quando eles apontam que, apesar das dificuldades enfrentadas pelos diferentes jovens brasileiros em seus contextos específicos, os(as) estudantes do ensino médio público de uma maneira geral se deparam quase sempre com as incertezas diante do trabalho, do lazer e dos projetos de vida. Assim, são caracterizados por darem valor a sociabilidades (grupos de amigos), a configuração espacial (espaço onde estão situados) e suas relações com as instituições (como trabalho e a própria escola). Nesse sentido, uma das perguntas questionava os estudantes a respeito da ideia que eles têm sobre o que é ser jovem. Assim, a pergunta "Para você, o que é ser jovem?" foi feita para 297 estudantes (como mostra a Tabela 2). 
Tabela 2 - Para você, o que é ser jovem?

\begin{tabular}{lcc}
\hline Para você, o que é ser jovem? & $\begin{array}{c}\text { Número de alunos } \\
\text { (em quantidade) }\end{array}$ & $\begin{array}{c}\text { Número de alunos } \\
\text { (em porcentagem) }\end{array}$ \\
\hline $\begin{array}{l}\text { Não ser velho e aproveitar a vida } \\
\text { com liberdade (juvenilistas) }\end{array}$ & 157 & $52,9 \%$ \\
\hline $\begin{array}{l}\text { Início da vida profissional, } \\
\text { responsabilidade e } \\
\text { amadurecimento (passageiros) }\end{array}$ & 57 & $19,2 \%$ \\
\hline Não souberam definir (invisíveis) & 83 & $27,9 \%$ \\
\hline Total & 297 & $100 \%$ \\
\hline
\end{tabular}

Tratou-se de uma pergunta aberta e, a partir das respostas, foram criadas três categorias: os jovens que acreditam que a juventude é uma fase para aproveitar a vida com liberdade (não sendo velho); os jovens que veem a juventude como uma fase de amadurecimento/responsabilidade (início da vida profissional); e aqueles que afirmaram não saber responder a pergunta. No intuito de classificar os grupos, o primeiro deles foi chamado de "juvenilistas"; o segundo grupo de "passageiros" e o terceiro de "invisíveis".

\section{Os jovens "juvenilistas"}

De todos os 297 estudantes que responderam à pergunta "Para você, o que é ser jovem?", $52,9 \%$ disseram que: ser jovem é não ser velho e uma fase para aproveitar a vida e ter liberdade. Mas o que representa esse posicionamento dos jovens? Por que a maioria dos jovens acredita que estão no momento para aproveitar a vida e ser livre? Se, atualmente, os meios de comunicação e atores políticos enxergam a juventude como uma fase da vida perigosa que necessita de "conserto"; esses jovens se veem em um momento de usufruir a vida. Como explicar essa "contradição"? Talvez as respostas dos jovens, primando à liberdade, estejam relacionadas à idade de moratória vital e moratória social, já trabalhada por Mannheim (1973) e Margulis e Urresti (1996).

Para além de definir a juventude apenas como um significado reduzido às discussões de classe, Margulis e Urresti (1996, p. 10), vão dizer que a juventude está conectada a uma série de variáveis, sendo ela uma condição que se articula no plano social e cultural baseada na idade "[...] como crédito energético e moratória vital, ou como distância frente à morte" e na geração a qual ela pertence, por meio da incorporação de sua memória social e das experiências vividas, sejam essas nos seios das diferentes classes sociais de origem, dos gêneros e, principalmente, pela moratória social advinda dessas pertenças.

Ao dizer que a juventude depende de uma moratória (espaço de possibilidades abertos a certos setores sociais e limitados a determinados períodos históricos) os autores falam que, em alguns âmbitos, os jovens se veem diante da possibilidade de adiar certas exigências (responsabilidades) requeridas, principalmente, pelo mundo do trabalho e da família. A moratória possibilita a esses jovens uma extensão do tempo para que eles possam usufruir práticas ligadas à liberdade e experimentação. A sociedade, por sua vez, vê essas ações juvenis com certa tolerância.

Considerando as questões relativas ao tempo, Margulis e Urresti (1996), acreditam que os jovens têm um "capital temporal”" que os coloca em condições favoráveis frente a outras gerações. Essas

4 De acordo com Margulis e Urresti (1996), capital temporal está relacionado a não preocupação com as características socais advindas com o tempo, como a sensação de (in)segurança, virilidade e o afastamento do sentimento da morte. Desse modo, quem possui o capital temporal, não se preocupa com essas questões. 
condições, ao entrarem em contato com a sociedade, sofrem alterações de acordo com a posição social ocupada por esses jovens. Sabe-se que nem todos os jovens possuem "capitais temporais". Desse modo, haverá jovens que vivenciam diferentes modos de experimentarem suas condições juvenis, em virtude do tempo que lhes são dados para tal. Já a moratória vital é condição essencial para o desenvolvimento da moratória social, pois, a partir dela, o tempo que os jovens possuem se converte em crédito social. Esse crédito refere-se, como bem ressaltou Groppo (2009), a um momento de orientação, livre experimentação e proteção dos jovens:

[...] la moratoria social puede ser presentada como una probabilidad otorgada principalmente a los miembros de ciertos grupos etarios, más probable para las clases media y alta que para las clases populares y para los varones respecto de las mujeres. Pero también hay otras variables que inciden en la condición de juventud, y esta es también accesible para otras clases sociales, sólo que bajo otras modalidades, sin tanto acceso a lo juvenil mas mediatizado, a la moratoria social, sus signos y sus privilegios, pero sin embargo también estas clases tienen sus jóvenes (que no siempre se presentan juveniles), que son considerados como tales en el marco de su medio social y las instituciones a las que pertenecen. (MARGULIS; URRESTI, 1996, p. 10).

Pela literatura, os jovens propícios a se enquadrem na moratória social seriam aqueles de classe média e alta, pois eles teriam possibilidades - respaldados pela família - de postergar seus momentos de entrada no mercado de trabalho para se dedicarem as práticas lúdicas, ao tempo livre e a expansão do crédito social. Os jovens dos setores mais populares teriam maiores dificuldades de ascender à moratória social, pois geralmente eles ingressariam mais cedo no mundo do trabalho (quase sempre precário). Assumindo mais responsabilidades, esses jovens carecem de tempo e dinheiro para viverem suas juventudes de formas mais prazerosa, despreocupada e livre. Poderíamos pensar, então, que os jovens que responderam o questionário fazem parte de uma classe média ou alta? Dois caminhos parecem se apresentar: o primeiro diz respeito à conquista por parte de alunos das escolas públicas ao "crédito social". O outro caminho, baseado nas limitações do próprio questionário, pode ser o de nem sempre a fala dos jovens representar aquilo que eles, de fato, estão vivenciando.

O primeiro caminho aponta para uma análise positiva, pois dá a possibilidade de jovens alunos(as) do ensino médio público vivenciarem suas experiências juvenis baseadas na perspectiva da moratória social. A premissa da liberdade e das vivências cotidianas longe de responsabilidades e problemas, ao que tudo indica, chegou aos jovens estudantes das escolas públicas de ensino médio. Sem dúvida, o fato de os jovens frequentarem a escola já indica que eles estão em uma posição possível de almejar uma juventude vivida com um pouco mais de direitos. A própria organização escolar atual se direciona nesse sentido quando notamos que a escola, além de um espaço para preparação para o mercado de trabalho e/ou faculdade, também se apresenta como um local de socialização, experimentação e encontro.

Assim, a noção de "desinstitucionalização" do curso da vida tratada por Dayrell (2003) e Pais (1990) é tencionada e a relação entre a juventude e a escola surge muito mais pelo viés dialético. Melhor seria, então, não trabalhar com a ideia de "desinstitucionalização do curso da vida", mas sim entender que as instituições (a escola) têm orientado os indivíduos jovens em outros sentidos (pelos encontros e experimentações), e, além disso, tem recebido, também, orientações deles dentro de seu espaço. A jovem A do C1 disse que ser jovem é: "morar com a mamãe, me divertir com as coisas mais idiotas, simplesmente, viver sem me preocupar com quase nada". O jovem E da mesma escola disse: "Ser jovem é ser uma pessoa livre e sem muitas preocupações com a vida".

$\mathrm{Na}$ escola P1 o jovem B escreveu que ser jovem é: "ser uma pessoa que não se preocupa muito com as responsabilidades, mas também se preocupa com o presente". O jovem C da mesma escola disse que: "é sair pras festas todo final de semana, ter amigos legais, se divertir, ter a mente aberta para novas experiências". Já no colégio $\mathrm{C} 2$, a jovem $\mathrm{H}$ disse que ser jovem é "ser um projeto que 
está em fase de construção, é ser inconsequente, só por ser, aproveitar ou achar que hoje é o seu último segundo". A estudante J, da mesma escola, relatou que ser jovem "é querer sair toda hora, ser animado, ser feliz e às vezes até sem sentido". Por fim, no colégio P2, para Z, ser jovem é "se divertir com coisas de jovem e não de adulto". Y, da mesma escola, ressaltou que ser jovem "é curtir a vida ao máximo, pois o dia de amanhã só Deus sabe".

Para esses 52,9\% dos jovens, a condição juvenil (ou a fase da juventude como eles responderam) é vivida de forma específica seja em relação à escola, ao trabalho e/ou a família. Para eles a prerrogativa de "aproveitar a vida com liberdade" e "fazerem o que quiserem" se estende para todas suas experiências cotidianas. Em relação à escola, eles podem vê-la e vivenciá-la sem muita preocupação com suas normas, regras e ritos; preferindo criar suas próprias ritualizações e normatizações nesse espaço. No que tange ao trabalho, a maioria dos jovens demonstram que não o vivenciam. Entre os jovens respondentes, $80,2 \%$ deles não possuem trabalho (e nem realizam estágio) e 19,8\% disseram trabalhar ou fazer estágio. Krauskopf (2004, p. 30), ao refletir sobre o conceito de moratória social na sociedade atual, vai dizer sobre sua relação com o mundo do trabalho,

Las características del mercado laboral tanto em los países llamados subdesarrollados como em aquellos situados em la avanzada mundial económico-política, hacen que la postergación y tiempo de espera implícitos em lamoratoria vean debilitado su sentido y evidencien más fuertemente las desventajas de la marginación en la toma de decisiones y el acceso a posiciones acordes com las capacidades y búsquedas juveniles.

De acordo com Abramo (1997), o fato de o jovem estar inserido no mercado de trabalho não o define como adulto, mas define a sua condição enquanto jovem e dá possibilidade de ele viver essa condição. Contudo, essa condição pode ser vivida de diferentes modos: uma juventude mais prazerosa e/ou uma juventude com mais responsabilidade. Além disso, nas respostas dos jovens o trabalho é visto, também, como um ritual e uma passagem para o mundo adulto. Assim, os jovens utilizam o trabalho como possibilidade de viver suas condições juvenis, mas também o tratam como um rito de passagem importante para o universo adulto. Isso demonstra que os jovens podem se importar em viver suas condições juvenis pautados pelo presente, mas não deixam de lado a importância na transição segura para a fase adulta, ou seja, pensam também no futuro.

A moratória social dos jovens que trabalham pode ser considerada a mesma daqueles que não trabalham? Pode-se dizer que não. $\mathrm{O}$ fato de os jovens terem um emprego, por si só, já não se adequa ao conceito de moratória social, sobretudo porque o tempo de experimentação e liberdade que esses jovens possuem apenas pode ser pensado nos momentos de não trabalho, já que o trabalho é visto como elemento legítimo de constituição de papéis sociais. O trabalho para esses 19,8\% dos jovens podem fazer com que eles se sintam integrados no que tange a participação social e a cidadania. Os jovens que trabalham, então, poderiam se enquadrar na ideia de moratória social? $\mathrm{O}$ trabalho quando relacionado à moratória social parece apresentar uma contradição: é a partir dela que os jovens parecem conquistar seus direitos à juventude.

De acordo com Mannheim (1973), a juventude representa uma espécie de recurso latente que toda sociedade dispõe e cabe à sociedade saber utilizar essa reserva vital juvenil. A importância da moratória social, para Mannheim (1973), dentre outras coisas, está na possibilidade de deixar que os jovens tenham a liberdade e a aproveitem de forma criativa em prol de uma mudança (melhoria) social. É importante, porém, que a liberdade de criação juvenil seja integrada a sociedade, sendo significativa para essa. Um exemplo cabível no sentido contrário a essa integração juventude/ sociedade defendida por Mannheim, parecem ser as novas políticas surgidas no Brasil, como por exemplo, aquelas em prol da redução da maioridade penal que desconsideram as potencialidades da juventude e, ao reprimir essa categoria, a trata como "problema social".

Em outras palavras, a moratória social considera a juventude como algo dúbio (GROPPO, 2009). Ao mesmo tempo em que era dada a juventude condições especiais para experimentação e vivência 
característica a essa fase da vida, também faziam com que ela fosse um momento de separação plena na vida social. Resumindo, os jovens ainda não eram considerados cidadãos, mas estavam se preparando para ser. Os jovens do questionário parecem dar outro sentido à noção de moratória social. Suas fases de experimentação se apresentam mais no sentido "presenteísta", ou seja, viver o aqui e o agora, ter possibilidades de fazer o que quiser sem sofrer sanções e menos no sentido de buscarem se tornar sujeitos responsáveis pela transformação, futuro e evolução da sociedade.

Assim, seus momentos "criativos" podem estar voltados, principalmente, para os momentos na qual eles preferem "não fazer nada", ou como Maffesoli (2005) defende: estar "junto à toa”. Em tom categórico e baseado nas classificações de grupos juvenis realizadas por Pais (1993), o grupo de jovens acima analisados serão categorizados como os “juvenilistas". A intenção de caracterizá-los utilizando um sufixo formador de adjetivos (istas) vem da ideia de que esses jovens, em seus discursos exprimem com clareza a noção de serem adeptos a determinados comportamentos e estilos juvenis que eles acreditam serem ideais para conceituar a juventude.

\section{Os jovens "passageiros"}

Aqui, a ideia é entender aqueles 19,2\% dos jovens estudantes que acreditam estarem em uma fase de amadurecimento, responsabilidade e início da vida profissional. Assim, discutirei como o trabalho, para além da escola, se torna uma "instituição" que parece influenciar esses jovens. Essa perspectiva nos coloca em tensão com aquelas que acreditam que na sociedade hodierna tem ocorrido uma "desinstitucionalização do curso da vida". Desse total de jovens, 35\% responderam que, atualmente, estão trabalhando ou fazendo estágio e $65 \%$ dos estudantes estão fora do mercado de trabalho.

Para eles, as características próprias embutidas na vida laboral funcionam como mecanismos de inserção social e/ou necessidade financeira. Ser responsável, amadurecer e iniciar na vida profissional são marcos de passagem da condição juvenil para a idade adulta!? O percentual de jovens (não) inseridos no mercado de trabalho pode ser analisado sob duas óticas: ou eles configuram-se como estatística dos indivíduos desempregados, mas sempre em busca de um trabalho; ou esses jovens reconhecem a importância do trabalho, mas optaram pela permanência no espaço escolar, com o intuito de uma melhor qualificação futura.

Já os $35 \%$ de jovens que trabalham, por sua vez, o fazem em parceria com seus estudos. É importante considerar que para esses estudantes o início de sua vida profissional é uma importante condição para que eles sobrevivam e construam suas identidades sociais. Assim, esses jovens dizem que, além da instituição escolar, o trabalho também é capaz de fazer juventudes (SPOSITO, 2005). Nesse aspecto, o estar junto atoa e a formação de neotribos juvenis pensadas por Maffesoli (2005) não são os únicos espaços capazes de construir identidades e identificações entre os jovens. A condição juvenil aparece novamente pautada pelas características institucionalizantes.

Considerar a entrada na vida laboral como característica pertencente à juventude engendra diversos significados. Jeolás e Souza Lima (2002) destacam que esses significados podem estar relacionados à ideia do trabalho como espaço de sociabilidade, como garantia de autonomia financeira e como uma instância socializadora (que garante maturidade e reponsabilidade). Dar importância para o trabalho e para a juventude enquanto um período de responsabilidade e maturidade nos revela que essa parcela dos estudantes ainda mantém certa normatividade e uma ideia de socialização contínua, tal qual aquela promulgada pela corrente geracional. O próprio trabalho em si já necessita de algumas capacidades referentes às disciplinas, normas e respeito com outros empregados e patrões. Isso faz com que o trabalho também seja um processo de socialização assim como a escola já é.

Desse modo, à luz de Pais (2009) o trabalho aqui se apresenta como uma característica de um rito de passagem para a fase adulta? Ritos de passagem podem se tornar ritos de impasse se esses jovens ficarem desempregados ou não conseguirem empregos. No entanto, esse rito de impasse 
prevalece apenas na prática, pois na cabeça desses jovens o trabalho e a pertença de responsabilidades são conquistas que os fazem amadurecer e serem pessoas diferentes daquelas que já foram quando mais novos. Assim, há uma mudança de ordem moral. Como afirmaram Jeolás e Souza Lima (2002), após aplicarem questionário com jovens, ideia de amadurecimento e responsabilidade tem intensa ligação com o trabalho. A responsabilidade surge como aspecto positivo relacionado ao trabalho, pois quando esses indivíduos ingressam no mundo laboral eles tornam-se mais responsáveis com horários e disciplinas, respeitando as normas estabelecidas.

No entanto, em nosso caso, apenas 35\% dos jovens podem se encaixar nessa perspectiva. Os outros jovens que não trabalham apesar de não viverem essa experiência, estão mais facilmente pré-dispostos a tal, pois consideram esse tempo importante para seus momentos de serem jovens, valorizando a ideia de responsabilidade e vida profissional. No colégio P2, o aluno X disse que ser jovem "é ser responsável na construção de um mundo melhor". Já W, da mesma escola, disse: "ter responsabilidade e querer com os estudos por que ninguém é nada sem os estudos". No colégio $\mathrm{C} 2$, a jovem L disse que "ser jovem é ter novos conhecimentos, pensar em algo para o futuro". $\mathrm{M}$, da mesma sala, ressaltou que: "ser jovem é ter a capacidade de se conhecer, interagir abertamente obtendo conhecimentos e aprendizados para suas escolhas e atitudes futuras".

No colégio P1, a aluna D relatou que "na minha opinião ser jovem é estar em uma fase em que damos direção a nossa vida, na profissão e no caráter". O jovem F, da mesma sala, disse que "pra mim, ser jovem é a fase que estamos começando a construir nosso futuro". Por fim, no $\mathrm{C} 1$, a jovem $\mathrm{U}$ disse que ser jovem "é uma fase de amadurecimento de descobrir o que é a vida no futuro". O aluno $\mathrm{O}$, da mesma sala, ressaltou que ser jovem "é ter responsabilidade com suas tarefas e trabalho e estudar". Os jovens responsáveis podem ser assim, não apenas por meio da experiência do trabalho, mas também por outras vivências que demandam "responsabilidades", como tarefas doméstica e a própria dinâmica escolar atual. O conceito de responsabilidade foi discutido por Jonas (2006). Para ele, discutir sobre responsabilidade é também falar sobre (im) prudência e irresponsabilidade. A responsabilidade estaria relacionada ao pensamento de novos princípios éticos, pois os que vigoram já foram deteriorados pela tecnologia do mundo moderno. Assim, articulando realidades objetivas e subjetivas, Jonas (2006) pensa a responsabilidade para além das ações individuais; é preciso pensar de forma coletiva, se tornando responsável, também, pelo futuro ao preservar o mundo para as novas gerações.

Assim, essa parcela de estudantes vive seus modos de serem jovens de forma diferente daqueles outros 52,9\% dos jovens (os "juvenilistas"). Para eles, a juventude está muito mais relacionada a um momento de ritos de passagem, no sentido de que tanto a escola como o trabalho são espaços propícios para se conquistar amadurecimento e responsabilidades. Desse modo, esses 19,2\% jovens parecem aceitar melhor a relação que possuem com as mais diversas instituições e são influenciados por elas. Na também busca de categorizar este grupo de jovens a partir de suas falas, irei chamá-los a partir de agora de "passageiros". Passageiros menos no sentido do rápido, breve e efêmero, e mais na essência daqueles que embarcaram em uma viagem na qual eles já parecem saber ou pelo menos tem a intenção de chegar a um local determinado. Estão, desse modo, se preparando para o futuro, com responsabilidade, amadurecimento e trabalho. Futuro este que parece ser a idade adulta.

\section{Os jovens "invisíveis"}

Ao se depararem com a pergunta "Para você o que é ser jovem?", 27,9\% dos pesquisados(as) optaram por deixar a resposta em branco. No entanto, esses jovens responderam as outras demais questões e, nesse sentido, tentarei aqui traçar um perfil desse grupo que, por seus motivos, optaram em não se definirem. Esse grupo possui idade entre 14 a 19 anos. Em sua maioria estão situados na faixa etária de 15 anos (26,5\%), 16 anos (32,5\%) e 17 anos (20\%). Em relação ao gênero, 38,5\% 
são do sexo feminino e $61,5 \%$ são do sexo masculino. No que tange ao estado civil, $86,7 \%$ jovens estão solteiros e 13,3\% estão namorando. $71 \%$ jovens não estão trabalhando enquanto $29 \%$ estão trabalhando ou realizando estágio.

Apenas quatro jovens desse grupo disseram não ter uma boa relação com seus coordenadores e professores e apenas um jovem disse não ter uma boa relação com seus colegas de escola. Todos os jovens desse grupo se definem como bons(as) alunos(as). Vale a pena destacar que os jovens pertencentes a este grupo dos que "não responderam" estão presentes em todas as quatro escolas pesquisadas. Quando perguntados sobre quais assuntos mais gostam de aprender dentro da escola, os jovens destacaram: música (19 estudantes), esporte (17 estudantes), tecnologia (12 estudantes), drogas (11 estudantes) e sexo (10 estudantes). Em relação aos assuntos que menos gostam de aprender na escola esses jovens que menos gostam de ver sobre: religião (31 estudantes), política (18 estudantes) e drogas (14 estudantes). Esses jovens também foram perguntados sobre o que gostariam de sugerir para melhorarem suas aprendizagens na escola. Duas sugestões apareceram, são elas: ter mais aulas práticas, utilizando outros métodos de ensino (24 jovens) e trabalhar assuntos do cotidiano juvenil (10 jovens). Vale a pena destacar que 49 estudantes optaram também por não responder esta questão.

A partir desta caracterização é possível dizer quem são esses jovens? Grosso modo, podemos afirmar que são jovens que não se comprometeram em responder o questionário, pois deixaram várias perguntas sem resposta, mesmo aquelas objetivas. Ainda assim, podemos afirmar que esse grupo se caracteriza por ser um grupo de jovens que se consideram bons alunos, não possuem problemas de relacionamento dentro do ambiente escolar e que não se interessam por assuntos relacionados à religião, política e drogas.

Outro ponto importante que permite um entendimento melhor deste grupo diz respeito a eles se interessarem em assuntos que, segundo os próprios, permeiam o cotidiano juvenil, como música, esporte e tecnologia. Nesse ponto esse grupo se caracteriza por, também, fazer uma crítica ao modelo escolar ao proporem que suas escolas passem a trabalhar baseada em outros métodos de ensino. No entanto, ainda assim, creio que seja precoce definir ou tentar caracterizar esse grupo. Chamarei esse grupo de jovens de "invisíveis" justamente pelo fato de estar diante da dificuldade de caracterizá-los.

Vemos que os jovens das quatro escolas se dividiram em três grupos ao responderem sobre suas condições juvenis. Os primeiros que acreditam que estão em um momento para aproveitar a vida e terem liberdade, o segundo grupo (menor em número) que enxergam suas vidas como momento de entrada no trabalho e possuir responsabilidade e o terceiro (dos "invisíveis"). Assim, como ressaltou Dayrell (2003), estamos diante de juventudes no plural. As respostas dos estudantes deixam transparecer que eles possuem características tanto da corrente geracional (os dois grupos consideram que estão vivenciando uma fase da vida) como também classista (o segundo grupo ao dar valor ímpar à categoria do trabalho como fundante desta fase). Nesse sentido, a ideia de que a juventude se apresentaria como um momento de afirmação de uma cultura juvenil e/ou um estilo de vida, também, esteve presente na resposta dos jovens. Nota-se, também, que a ideia das correntes geracionais e classistas aparecem nos discursos do cotidiano juvenil e, como nos lembra Pais (2009), é preciso que saibamos, enquanto pesquisadores, nos relacionar com essas correntes teóricas.

\section{Conclusão}

Este artigo procurou compreender quem são os jovens que frequentam o ensino médio. Cientes de que a aplicação de questionário com perguntas abertas não dá conta de compreender o todo, acreditamos que é fundamental que pesquisas futuras lancem mão de outras ferramentas metodológicas na tentativa de captar os sentidos que os jovens atribuem as suas vidas.

A presença dos jovens "passageiros", dos "juvenilistas" e dos "invisíveis" demonstra que a escola é uma instituição que recebe estudantes heterogêneos, com perspectivas de vida diferentes. 
Nesse sentido, parece que, atualmente, temos enfrentado um dilema que envolve os "jovens do ensino médio" e os “jovens no ensino médio". Pensar em "jovens do ensino médio" significa pensar em uma cultura juvenil que cotidianamente reflete sobre seus modos de viver, experimentando e vivenciando o ensino médio de modo a (re)construir, por meio de críticas, confrontos e debates, novos valores e sentidos para seus projetos de vida que, sem dúvida, envolve a escola.

Para além dos modos homogêneos de pensar os estudantes e suas escolas, as respostas dos jovens pesquisados têm muito a nos dizer. Podemos afirmar que o diagnóstico que os autores citados neste artigo fazem sobre a juventude na sociedade atual se assemelha, de certo modo, as noções que os jovens têm de si e de suas vidas. Sem dúvida, as respostas dos "passageiros", "juvenilistas" e "invisíveis" reforça a crença de que a juventude hodierna têm vivenciado (ou sofrido) processos heterogêneos de socialização e isso faz com que os jovens passem a serem mais percebidos socialmente como sujeitos capazes de tomar decisões e se posicionarem, inclusive dentro do ambiente escolar.

Não estamos falando aqui de diferentes modelos de escola ou de escolas que só existem no plano das ideias. A mesma escola e as mesmas salas de aula comportam "juvenilistas", "passageiros" e "invisíveis". A instituição escolar não é obrigada a pautar sua trajetória mirando apenas projetos futuros; ela também pode se realizar com projetos presentes. A formação para o trabalho pode aparecer junta a formação propedêutica e a outras tantas possíveis. Portanto, é no dia a dia escolar que os jovens fazem as suas juventudes e refletem sobre ela.

\section{Referências}

ABRAMO, Helena Wendell. Considerações sobre a tematização social da juventude no Brasil. Revista Brasileira de Educação, Rio de Janeiro, n. 5-6, p. 25-36, maio/dez. 1997.

ALMEIDA, Felipe Quintão de; BUNGENSTAB, Gabriel Carvalho. Práticas corporais nas escolas de ensino médio situadas em Vitória/Espírito Santo. Pensar a Prática, Goiânia, v. 19, n. 1, p. 156-168, jan./mar. 2016.

BARDIN, Laurence. Análise de conteúdo. Lisboa: Edições 70, 1988.

BUNGENSTAB, Gabriel Carvalho. Dando voz aos estudantes na cidade de Goiânia/GO: investigações sobre a "crise" entre os jovens e o ensino médio. 2016. Tese (Doutorado em Sociologia) - Universidade Federal de Goiás, Goiânia, 2016.

BUNGENSTAB, Gabriel Carvalho. A presença do termo juventude na produção científica da Educação Física brasileira: para onde vamos? Revista Motrivivência, Florianópolis, v. 32, n. 62, p. 1-14, 2020.

CHARLOT, Bernard. Da relação com o saber às práticas educativas. São Paulo: Cortez, 2013.

DAYRELL, Juarez. O Jovem Como Sujeito Social. Revista Brasileira de Educação, Rio de Janeiro, n. 24. p. 4-13, dez. 2003.

DAYRELL, Juarez. A escola "faz" as juventudes? Reflexões em torno da socialização juvenil. Educação \& Sociedade, Campinas, v. 28, n. 100, p. 1105-1128, out. 2007.

DAYRELL, Juarez. O ensino médio no Brasil e seus desafios: o que dizem os jovens sobre os processos de exclusão escolar. Linguagem, Educação e Sociedade, Teresina, v. 18, p. 77-102, 2013.

DAYRELL, Juarez; CARRANO, Paulo. Juventude e Ensino Médio: quem é este aluno que chega à escola. In: DAYRELL, Juarez; CARRANO, Paulo; MAIA, Carla Linhares (org.). Juventude e Ensino Médio: sujeitos e currículos em diálogo. Belo Horizonte: Editora UFMG, 2014. p. 101-135.

DUBET, François. Sociologia da Experiência. Lisboa: Instituto Piaget, 1994.

EISENSTADT, Shmuel Noah. De geração a geração. São Paulo: Perspectiva, 1956.

GIDDENS, Anthony. As consequências da modernidade. São Paulo: Editora UNESP, 1991.

GROPPO, Luis Antonio. O funcionalismo e a tese da moratória social na análise das rebeldias juvenis. Estudos de Sociologia, São Paulo, v. 14, n. 26, p. 37-50, dez. 2009. 
JONAS, Hans. O Princípio Responsabilidade: ensaio de uma ética para uma civilização tecnológica. Rio de Janeiro: Editora PUC-Rio, 2006

JEOLÁS, Leila Sollberger; SOUZA LIMA, Maria Elena Melchiades Salvadego de. Juventude e trabalho: entre "fazer o que gosta" e "gostar do que faz". Revista Mediações. Londrina, v. 7, n. 2, p. 35-62, jul./dez. 2002.

KRAUSKOPF, Dina. Comprension de la juventude: El ocaso del concepto de moratória psicossocial. Revista de Estudios sobre juventud, México, v. 8, n. 21, p. 26-39, out. 2004.

MACEDO, Roberto Sidnei. A etnopesquisa crítica e multirreferencial nas ciências humanas e na educação. Salvador: Edufba, 2000.

MAFFESOLI, Michel. Cultura e comunicação juvenis. Comunicação, mídia e consumo. São Paulo, v. 2, n. 4, p. 11-27, jul. 2005.

MANNHEIM, Karl. Diagnóstico de nosso tempo. 3. ed. Rio de Janeiro: Zahar, 1973.

MARGULIS, Mario; URRESTI, Marcelo. La juventudes más que una palabra. In: Margulis, Mario (org.). La juventudes más que una palabra. Buenos Aires: Biblos, 1996. p. 1-13.

MARTINS, Carlos Henrique; CARRANO, Paulo. A escola diante das culturas juvenis: reconhecer para dialogar. Educação, Santa Maria, v. 36, n. 1, p. 43-56, jan./abr. 2011.

PAIS, José Machado. Culturas juvenis. Lisboa: Imprensa Nacional Casa da Moeda, 1993.

PAIS, José Machado. A construção sociológica da juventude: alguns contributos. Análise Social, Lisboa, v. 25, n. 105106, p. 139-165, 1990.

PAIS, José Machado. Jovens e cidadania. Sociologia, Problemas e Práticas, Lisboa, n. 49, p. 53-70, 2005.

PAIS, José Machado. A juventude como fase de vida: dos ritos de passagem aos ritos de impasse. Saúde e Sociedade, São Paulo, v. 18, n. 3, p. 371-381, 2009.

PAIS, José Machado; CAIRNS, David; PAPPÁMIKAIL, Lia. Jovens europeus: retratos da diversidade. Tempo Social: Revista de Sociologia da USP, São Paulo, v. 17, n. 2, p. 109-140, 2005.

PARSONS, Talcott. Age and sex in the social structure of the United States. American Sociological Review, Bloomington, v. 7, n. 5, p. 604-616, 1942.

REIS, Rosemeire. Juventudes no ensino médio: os sentidos atribuídos à escola e aos planos de futuro. Latitudes, São Paulo, v. 6, n. 1, p. 131-155, jul./set. 2012.

SPOSITO, Marilia Pontes. Algumas reflexões e muitas indagações sobre as relações entre juventude escola no Brasil. In: ABRAMO, Helena Wendel; BRANCO, Pedro Paulo Martoni (org.). Retratos da juventude brasileira: análises de uma pesquisa nacional. São Paulo: Editora Instituto Cidadania: Editora Fundação Perseu Abramo, 2005.

Data de submissão: 04/01/2021

Data de aprovação: 16/01/2021 